Preprint: André O. Laplume, Bent Petersen, Joshua M. Pearce, Global value chains from a 3D printing perspective, Journal of International Business Studies 47(5), 595-609 (2016). doi:10.1057/jibs.2015.47

\title{
Global Value Chains from a 3D Printing Perspective
}

For the JIBS Special Issue on Internationalization in the Information Age

André O. Laplume

School of Business and Economics,

Michigan Technological University

1400 Townsend Drive.

Houghton, Michigan, 49931

906-487-3267

Contact author: aolaplum@mtu.edu

Bent Petersen

Department of Strategic Management and Globalization

Copenhagen Business School

Solbjerg Plads 3, 2000 Frederiksberg, Denmark

Room: KIL/14A-2.59

$+4538152510$

bp.smg@cbs.dk

Joshua M. Pearce

Department of Materials Science \& Engineering

and Department of Electrical \& Computer Engineering,

Michigan Technological University

1400 Townsend Drive.

Houghton, Michigan, 49931

906-487-1466

pearce@mtu.edu

\begin{abstract}
This paper outlines the evolution of additive manufacturing technology, culminating in 3D printing, and presents a vision of how this evolution is affecting existing global value chains in production. In particular, we bring up questions about how this new technology can affect the geographic span and density of global value chains. Potentially, wider adoption of this technology has the potential to partially reverse the trend towards global specialization of production systems into elements that may be geographically dispersed and closer to the end-users (localization). This leaves the question of whether in some industries diffusion of 3D printing technologies may change the role of multinational enterprises as coordinators of global value chains by inducing the engagement of a wider variety of firms, even households.
\end{abstract}

Keywords: additive manufacturing; 3D printing; global value chains; geographic span; geographic density 
Preprint: André O. Laplume, Bent Petersen, Joshua M. Pearce, Global value chains from a 3D printing perspective, Journal of International Business Studies 47(5), 595-609 (2016). doi:10.1057/jibs.2015.47

\section{INTRODUCTION}

A key capability of multinational enterprises (MNEs) is the organization and effective coordination of global value chains (GVCs) (Oviatt \& McDougall, 1994). However, this view is bumping up against the information age (Globerman, Roehl, \& Standifird, 2001), which may have dramatic consequences for the configuration of GVCs in terms of their geographic span and density. According to its advocates, 3D printing now threatens to upend retailers, distributers (middle-men), and manufacturers of tangible goods, by introducing a new paradigm of industrial production via the layer-by-layer additive construction of 3D objects from digital designs (Lipson \& Kurman, 2013).

3D printing technology has moved beyond its early success as an acceleration of innovation cycles via rapid prototyping and is now being applied in the manufacture of a wide array of products. The Economist (2012), and others, suggest that the technology is spawning the next industrial revolution (Hopkinson, Hague, \& Dickens, 2006). Developers of the technology argue that 3D printing provides a path to sustainable development for low-income countries, and many authors argue that the technology will lead to a world in which personal fabrication and peer production will replace most industrial processes (Gershenfeld, 2008; Moilanen \& Vadén, 2013; Lipson \& Kurman, 2013). Despite its current diffusion into marginal markets, the potential effects of 3D printing technology can be viewed in various lights. Proprietary 3D printing and open-source 3D printing are being used in some high-end manufacturing (e.g., for aircraft-engine components and automobile production), but desktop 3D printing (e.g., households making household items) also holds promise (Economist, 2012). A few years ago, desktop 3D printers remained a pursuit of hobbyists, innovators, and early adopters, and had yet to cross into mainstream applications, possibly owing to the technology's limitations (e.g., size limits, resolution, ease of use, speed, and complexity of materials). However, the technology now appears more economical than more labor-intensive "cut-and-mold” manufacturing techniques (Berman, 2012; Nyman \& Sarlin, 2013).

Recent work shows that 3D printing is economically viable for US households (Wittbrodt et al., 2013). As they adopt the technology, households and 3D print shops may gain a bigger share of potential industry earnings (Dedrick, Kraemer \& Linden, 2010) because 3D printing puts the means of production back in their hands and undermines some of the complementary asset advantages of MNEs (Dunning, 2001; Ghoshal \& Bartlett, 1998). However, it does not do so equally in all industries, rather, as we will show, the technology's rise has been steeper in some industries than in others. We theorize that several dimensions, including the type of materials, the need for customization, and for speedy delivery, and low cost (for printing complex objects), may be the disruptive drivers of this technology.

The key implication of this technology for international business research is that it has the potential to reshape GVCs by altering their geographic span and density. On this background the paper proceeds as follows: First we provide a brief introduction to, and status of, the new manufacturing technology: its properties and applications. In the next section we discuss the scope of the additive manufacturing: which industries are fully 'exposed' to 3D printing, which only moderately, and which industries seem immune to the technology. Next follows an account for the GVC phenomenon and its underlying drivers and impediments. In the next three sections the GVC determinants-factor cost differentials, scale economies, and factors impeding global specialization - are analyzed from an additive manufacturing perspective. We juxtapose the various GVC determinants and additive manufacturing in order to clarify potential implications of the new technology to configuration of production systems, raising questions for future research. A final section concludes and point out limitations of the study.

\section{BACKGROUND ON ADDITIVE MANUFACTURING}

A 3D printer is a device that is able to construct a three-dimensional solid object of any shape from a digital design. Historically, 3D printing has been referred to as "additive manufacturing" because it uses an "additive" process in which layers of material in different 2D shapes are successively added. These 2D 
Preprint: André O. Laplume, Bent Petersen, Joshua M. Pearce, Global value chains from a 3D printing perspective, Journal of International Business Studies 47(5), 595-609 (2016). doi:10.1057/jibs.2015.47

shapes build upon each other into 3D objects. This distinguishes 3D printing from subtractive methods of manufacturing in which one starts with a block of material and mills away unnecessary material until the final shape is obtained.

Some versions of 3D printers have been around since the 1970s, but they were not commercialized or widely diffused. Improvements in technology (e.g., Hull, 1986) led to the development of 3D printers that were largely used for rapid prototyping or secondary manufacturing techniques (e.g., forming tools for traditional manufacturing techniques, such as injection molding). In the 1980s, 1990s, and early 2000s, 3D printing evolved within the confines of the R\&D departments of a small oligopoly of firms (e.g., 3D Systems, zCorp, Stratasys, and Objet Geometries), leading to some variations in terms of resolution, color availability, and time required for printing. These printers cost between USD 20,000 and USD 300,000 (Bradshaw, Bowyer \& Haufe, 2010). Those machines that were used for production in metal often cost more than USD 500,000. Despite their high costs, these machines were widely adopted, primarily by firms seeking rapid prototyping capabilities. Prospects for much wider adoption in terms of manufacturing at the household or local shop level were limited by the high price tag. ${ }^{1}$ However, in 2004, a professor in the UK launched an open-source 3D printer project called the RepRap (self-replicating rapid prototyper) (Bowyer, 2014; Jones et al., 2011; Sells, Bailard, Smith, Bowyer, 2010). The process used in RepRap 3D printers is called fused-filament fabrication (FFF). The name refers to essentially the same process as fused-deposition modeling (FDM), but it is used to avoid trademark infringement. The goal of the RepRap project is to make a 3D printer that is capable of not only printing various products but also replicating itself. Recent versions of the RepRap can print approximately $50 \%$ of their own parts, dramatically reducing costs (Pearce, 2015).

Open-source innovation includes more participants than proprietary or closed-source innovation within firms, and it is less encumbered by intellectual property issues (Chesbrough, 2003; Huizingh, 2011; Yu \& Hang, 2011). Thus, the trajectories of improvement are steeper (Foss and Pedersen, 2004) than they are for traditional manufacturing technologies. Improvements are essentially continuous, as new designs are published almost daily. While the number of improvements is hard to quantify, Reprap.org (2012) shows that unique versions of the Darwin were introduced 20 times between 2006 and 2009, 41 times in 2010, and 99 times in 2011. In 2012, 43 unique versions were introduced in Q1 alone. Similarly, repositories such as Thingiverse, which houses nearly one million free digital designs, are continually posting new designs for objects that can be printed (Wittbrodt et al., 2013). Rough sales figures suggest that only around 70,000 low-cost 3D printers were sold prior to 2013, whereas 2013 was on track for sales of about 145,000 units. This represents a doubling of the total amount in just one year. ${ }^{2}$ At the moment, most designs (for printed objects) are hard to copyright and copyright laws can be bypassed through the introduction of small changes in the overall design (Bradshaw et al., 2010). Therefore, Thingiverse, YouMagine, Stanford 3D Scanning Repository, Github, Repables, Pirate Bay Physibles, Fab Fabbers, Cubehero, Bld3r, Libre 3D, and other repositories of public-domain designs may blossom. ${ }^{3}$ Interestingly, one of the goals of the core 3D printing research community (e.g., RepRap) is to make 3D printers printable and to take control of the machines themselves out of the hands of incumbents (i.e., by building self-replicating printers). Although this goal has yet to be fully achieved, the technical potential is developing rapidly. However, some of the technologies needed to build better but still inexpensive 3D printers are currently being held up by several patents. For instance, laser patents owned by incumbents make it difficult for researchers to experiment with alternatives to fused filament additive manufacturing (e.g., laser sintering). ${ }^{4}$

When the core FDM patent expired in 2009, the RepRap was quickly followed by hundreds of derivative innovations created by individuals and companies all over the world. Some of these remained open-source (like Ultimaker) or at least "accessible source”, such as Type A Machines. Others went "closed source", such as the MakerBot. Many of these 3D printing companies that chose to remain opensource in order to leverage the rapid innovation cycles in the RepRap community have continued the tradition of designing printable parts. For example, the Lulzbot, a commercialized 3D printer 
Preprint: André O. Laplume, Bent Petersen, Joshua M. Pearce, Global value chains from a 3D printing perspective, Journal of International Business Studies 47(5), 595-609 (2016). doi:10.1057/jibs.2015.47

manufactured by Aleph Objects, is made in a factory where hundreds of Lulzbot printers print parts for future printers. These open-source 3D printers not only provide the mechanical designs for the maker community to improve upon, but they are also made with open-source electronics (e.g., Arduino microcontrollers). Similar to open-source software, those who use open-source hardware are expected to provide the community with information on any improvements based on the open designs. This leads to rapid innovation and improved machines.

Between 2009 and 2013 the standard RepRap cut the cost of 3D printers to less than USD 1,000, which was less than one tenth of the cost of the 3D printers provided by the commercial oligarchy at the time. As they were free to innovate without negotiating licenses or paying royalties, open-source supporters of low-cost 3D printers exploded onto the scene during these years. Dozens of companies, offering different versions of open-source printers, appeared. Many of them received funding from crowdsourcing websites, such as Kickstarter and Indiegogo. This intensive fermentation period allowed the technology to improve rapidly from year to year, and the cost of a basic machine fell to just a few hundred dollars, although assembly is sometimes required. In general, commercial proprietary 3D printers are limited in terms of applicability in order to maintain quality and reliability, while the RepRap and other open-source 3D printers are more flexible, as shown in Table 1.

Insert Table 1 about here

Notably, although both conventional and RepRap 3D printers print in a variety of materials, including ceramics and metal, the vast majority are limited to printing in plastic. With RepRap driving down the cost of 3D printing, the major firms now also offer lower-cost (i.e., less than USD 2,000) 3D printers capable of printing in plastic in a limited fashion (e.g., only in one plastic, which the company makes available in a cartridge). Examples of recent improvements in open-sourced, low-cost 3D printers include: printing using a greater variety of materials, such as metals (Anzalone, Zhang, Wijnen, Sanders, \& Pearce, 2013) and conductive materials; simultaneous printing with more than one type of material; printing with multiple printer heads (Anzalone, Wijnen \& Pearce, 2015), which allows for higher volumes; improved resolution; greater area or volume; and ease-of-use improvements aimed at making assembly, maintenance, and use accessible to consumers.

The above account for additive manufacturing does not establish whether or not this technology should be considered "disruptive" or a "general purpose technology" understood as a new method of production with a protracted aggregate impact (Jovanovic and Rousseau, 2005). Examples of such technologies include electricity and information technology. The degree of "disruption" depends not least on the extent to which the new technology changes the affordability of the products produced (and thereby the consumption pattern) but also on the extent to which the new technology entails a change in the composition of factor inputs (Danneels, 2004; Tushman \& Anderson, 1986). Hence, in the cases where 3D printing substitutes for labor-intensive manufacturing processes this certainly implies a disruption in the industry in question. However, in cases where the substituted manufacturing processes are already highly automated the factor inputs (with low labor-capital ratios) basically remain the same. So, when we juxtapose 3D printing and "traditional" or "conventional” manufacturing technology this is, in practice, an overgeneralization. In a way, we may consider 3D printing as a variety of automated manufacturing and, as such, we implicitly assume "conventional" and "traditional" manufacturing technology to be less automated and more labor-intensive. The other issue, whether additive manufacturing is an emerging "general purpose technology" depends foremost on its expected diffusion in the various manufacturing industries. We look at this in the next section.

\section{DIFFUSION OF 3D PRINTING TECHNOLOGY IN DIFFERENT INDUSTRIES}


Preprint: André O. Laplume, Bent Petersen, Joshua M. Pearce, Global value chains from a 3D printing perspective, Journal of International Business Studies 47(5), 595-609 (2016). doi:10.1057/jibs.2015.47

This section is intended to give a sense of the diffusion of the 3D printing technology in different manufacturing industries and is thus necessary coarse-grained. Although the construction industry may also be affected by this technology, with several innovators printing houses and buildings with concrete, the manufacturing industry is more relevant for global value chains and hence is the focus here.

Based on their independent assessments of the current and future diffusion of 3D printing technology the authors coded each of the industries listed in the manufacturing sector according to the International Standard Industrial Classifications (ISIC). We then compared response explanations and recoded based on discussions. The resultant coding was used to categorize the industries into the four quadrants of Table 2.

Insert Table 2 about here

The following subsections identify and explain (1) industries with no, or low, current or future adoption of the 3D printing technology, (2) industries currently being affected by the technology, and (3) industries into which the new technology is likely to diffuse in the future.

\section{Unaffected Industries}

Some industries are unlikely to be affected by the 3D printing technology—neither today, nor in the future. Products that are made of natural materials (e.g., solid wood, cork, leather, natural textiles, paper, and tobacco products) are largely unsuitable as filament for 3D printing and therefore unlikely to be affected (although there are already several types of wood powder based filaments). These products tend to be desired in part due to their natural properties such as tensile strength, grain, or texture and, therefore are less likely to be affected.

Another significant area that is unlikely to be directly affected by the technology is the production of most industrial raw materials (e.g., petroleum products, and basic metals). The production of the tools to harvest these materials may be 3-D printed and these materials can become the filament for 3-D printing, but cannot be directly printed. Similarly, industries that break down or fragment materials are unlikely to be affected by the technology.

\section{Industries Currently Being Affected}

Simple products are currently most affected by 3D printing technology. These products tend to be small in size, made of just one material, and do not have many interacting parts, making them ideal candidates for low-cost 3D printing. Hence, the manufacture of jewelry, musical instruments, sports goods and toys, and medical instruments, has to a large extent already adopted the 3D printing technology. For instance, toys and games are so popular that they warrant their own section in the storefront of the largest repository (Thingiverse). Most of the open-source printers currently on the market print with plastic and the vast majority of the designs currently available for download on repositories (e.g., chess pieces, construction toys, dice, games, mechanical toys, playsets and puzzles) are intended to be printed in plastic. In general, those made of a single raw material such as plastic, ceramics, or metals, are already feasible. Both the manufacture and repair of machinery and equipment is also currently being affected by 3D printing technology. 3D printing replacement parts for machines is becoming commonplace. However, the best example of this trend is the advancement of the printing of 3D printers themselves. As earlier mentioned, many of these machines are designed so that their parts can be printed.

\section{Industries to be Affected in the Future}

Some industries are currently minimally affected, but are likely to adopt the 3D printing technology in the future. Due to space limitations, the focus here will be on four exemplary industries (foodstuff, wearing apparel, automobiles, and medicine), which show the breadth of application of the technology. 
Preprint: André O. Laplume, Bent Petersen, Joshua M. Pearce, Global value chains from a 3D printing perspective, Journal of International Business Studies 47(5), 595-609 (2016). doi:10.1057/jibs.2015.47

The manufacturing of food products is likely to be affected in the future due to the ability of 3D printers to create complex geometries. Current examples are limited to 3D printers that can make elaborate shapes from chocolate and candy. For instance, chocolates can be shaped into roses and wedding cakes can be elaborately customized. However, this same technology may also be expanded to include printing confectionary products, pastas, crackers, and pizzas. For instance, NASA recently invested USD 125,000 in a 3D printer that can print a pizza fit for astronauts (Opam, 2014). It is less likely that staple foods will be affected, but to the extent that presentation matters, restaurants, specialty food shops, and dessert shops may adopt the technology.

Manufacturing of wearing apparel is currently limited to fashion products (plastic clothing), such as bikinis (currently available from Shapeways), and specialized fashion applications with complex geometries. Shoes and boots with intricate patterns, impossible to create with conventional methods, have begun to appear on the fashion runways. Flowing dresses have been successfully designed to take advantage of 3D printing, and more is sure to follow (Flaherty, 2014; Lussenburg, Van der Velden, Doubrovski, Geraedts \& Karana, 2014). As 3D printing media expand to include other synthetic materials, such as nylon, the diffusion of the technology in the apparel industry will increase accordingly. Applications in textiles and wearable clothing highlight the important role that the technology will play in allowing for high levels of customization and customer responsiveness. Because in the fashion industry, there are few patents or copyrights to contend with, the ability of manufacturers to produce unique designs is likely to push them toward the technology. Printing apparel close to the customers can help to ensure the artificial (or real) scarcity that drives fashion trends.

Manufacturing of fabricated metal products are currently just barely being affected, but 3D printing metal is a hot topic today. For instance, Anzalone et al. (2013) created a low cost (USD 2,000) open-source 3D printer based on the RepRap design. A Google Scholar search reveals that inventions and scientific papers written about 3D printing with metal are increasing at a rate of 55\% per year (686 in 2011; 978 in 2012; 1,570 in 2013; 2,530 in 2013). Relatedly, computers, electronics and electrical equipment are likely to be affected along with the development of 3D printers capable of printing conductive materials. The emergence of 3D printing with metal will also affect motor vehicles and other transport equipment, especially as the printers increase in size.

Products made of clays and ceramics (Scheithauer, Schwarzer, Richter, \& Moritz, 2015) are also candidates for 3D printing. Google Scholar reveals an increase of about 45\% per year for ceramic 3D printing research (433 in 2011; 650 in 2012; 866 in 2013; 1330 in 2014). The development of printable ceramics has been driven by medical applications, such as porous scaffolding materials to replace bone and various orthopedic implants. However, the refinement of the technology in this niche is likely to allow it to be used in many other applications. Finally, there is some indication that more complex chemicals and medicines may be 3D printed in the future from the now early development of 3D printed reactionware that allows for unprecedented control of reaction chemistry and analysis (Symes et al., 2012; Kitson, Rosnes, Sans, Dragone, \& Cronin, 2012; Kitson, Symes, Dragone, \& Cronin, 2013).

Based on the above analysis four parameters seem to explain the extent of the diffusion of 3D printing technology in a given manufacturing industry: (i) the nature of the industrial process, including the type of input materials, (ii) the need for speedy delivery, (iii) the need for product customization and quick responsiveness to changing consumer preferences, and (iv) the need for low-cost, low-volume products (such as prototypes).

Firstly, the nature of the industrial process: 3D printing is unusable for transformation or refinement of raw materials, such as crude oil into petroleum products or iron ore into metals. Along these lines, the type of materials used as inputs for the manufacture determines the suitability of 3D printing; some materials are just not suitable for filament (e.g., solid wood and marble) in 3D printing (although it should be pointed out that both materials can be used as additives in composite 3D printer filaments such as laywood filament made from $40 \%$ recycled fine wood sawdust and polymer binders). 
Preprint: André O. Laplume, Bent Petersen, Joshua M. Pearce, Global value chains from a 3D printing perspective, Journal of International Business Studies 47(5), 595-609 (2016). doi:10.1057/jibs.2015.47

Secondly, 3D printing appears more feasible in industries, or industry segments, where customization and quick responsiveness to fast-changing consumer preferences and market conditions are important rather than in commodity production based on economies of scale. This echoes the heralding of new, flexible production paradigms coined as mass customization (e.g. Pine 1993), delayed product differentiation (e.g. Lee and Tang, 1997), and reconfigurable manufacturing systems (e.g. Mehrabi, Ulsoy and Koren, 2000).

Thirdly, the need for swift delivery may be a critical dimension. This is the case where large-scale and emergency operations are disrupted until the arrival of spare parts that are impractical to stockpile on site. For years now the U.S. Army has been working with 3D printers, mostly from an experimental point of view, but in some cases using them in actual combat zones, to print out parts which may be needed urgently. In April 2014, another branch of the U.S. Military, the United States Navy, installed a metal 3D printer on board the US Essex-a Wasp-class amphibious assault ship ${ }^{5}$. Another example is engine defects on large merchant vessels with precious cargo on board. Just few days of delay may be very costly, that is, a matter of millions of dollars in demurrage. Accordingly, shipping companies are installing $3 \mathrm{D}$ printers that can produce the spare parts needed to repair engine defects. ${ }^{6}$ The need for swift delivery in new, innovative business models may imply adoption of 3D printing. As a hypothetical example, the global retail chain, Zara, a subsidiary of Spanish Inditex, has swift, even weekly, turnover of their shop collections, as an integrated part of their successful business model. Their need for swift delivery of fashion items (for which warehousing is not an option) is preventing the retailer from sourcing globally. Instead, factories in the proximity of the retail outlets deliver the apparel (New York Times Magazine, 2012). One may easily imagine 3D printing as a lever of this strategy of quick response to customer needs. Our conclusion is that needs for swift delivery of non-storable manufactures in general impels 3D printing.

Finally, low cost may be a key dimension in the sense that the technology allows complex shapes to be printed rather cheaply compared with other manufacturing technologies. This is particularly relevant in the case of prototyping, but also with regard to one-off prints, such as replacement parts.

After this account of the nature, dimensions and scope of 3D printing we now turn to a discussion of how this may translate into effects on GVCs' span and density. The remainder of the paper will be devoted this discussion.

\section{D PRINTING AND GLOBAL VALUE CHAINS}

A significant proportion of the world's manufacturing is the result of an international division of labor coordinated by MNEs (UNCTAD, 2013). Whereas the international division of labor in manufacturing has existed for centuries (Smith, 1776; Ricardo, 1817), MNE coordination did not take off until the 1960s, when US multinationals began offshoring labor-intensive manufacturing processes to low-cost production zones in countries like Mexico and the Philippines. This surge in offshoring was supported by the establishment of tax-exempt and tariff-free export production zones in a number of developing countries in tandem with the US government's introduction of tariff provisions permitting duty-free reentry to the USA of US-made components sent abroad for further processing or assembly (Maskell, Pedersen, Petersen \& Dick-Nielsen, 2007). In the 1980s, the label "global value chain” was applied to this MNEcoordinated division of labor. The label referred to the popular value-chain template (Porter, 1985). As an international extension of his value-chain concept, Porter introduced the "global value chain" in which he differentiated between dispersed and concentrated global value-chain configurations. The latter described the sophisticated global specialization of the various value-chain activities of multinational companies (Porter, 1986). In the ensuing years, scholars in international business (e.g., Dunning, 1993), development economics (e.g., Gereffi, Humphrey \& Sturgeon, 2005), and economic geography (e.g., Mudambi, 2008) pointed to the importance of contractual modes of governing global value chains. Instead of using hierarchical governance, MNEs often preferred subcontracting as an effective governance mechanism. 
Preprint: André O. Laplume, Bent Petersen, Joshua M. Pearce, Global value chains from a 3D printing perspective, Journal of International Business Studies 47(5), 595-609 (2016). doi:10.1057/jibs.2015.47

Irrespective of the governance mode, global value chains have in common the international specialization of business activities_-including manufacturing-coordinated by an MNE. Specialization on a global scale, which is the hallmark of global value chains, implies the geographical diversification of the value chain as a whole as well as the locational concentration of individual value-chain activities. The substantial lowering of import barriers for manufacturers as a result of international trade negotiations in the 1990s and 2000s, the containerization of cargo transport, and the advancement of information and communication technologies fueled an unprecedented global specialization of value-chain activities, including manufacturing (Dicken, 2014). The vertically disintegrated and fine-sliced global production network is itself a relatively recent trend (at least seen in the historical perspective of the industrial revolution) which the $3 \mathrm{D}$ printing technology may partially offset. This recent geographical concentration of manufacturing (and concomitant physical separation from customers) is perhaps best illustrated by the emergence of China as the "factory of the world" (METI, 2002). Today, the bulk of the world's electronic equipment is produced in China. Moreover, the country is the largest exporter of clothing, toys, domestic appliances, and merchant ships (WTO, 2013). Global value chains for sports shoes, furniture, and smart phones, orchestrated by Nike, Ikea, and Apple, respectively, serve as examples of how production has moved further away from end-users; though, the emergence of China as not only "the factory of the world" but also the world's largest market for consumer products moderates this disparity.

Our first step in translating the technological scope of 3D printing into GVC effects is to specify the relevant antecedents of MNE-coordinated global production networks (sometimes labeled "the global factory”, see, e.g., Buckley \& Ghauri, 2004). Our specification revolves around answering the questions if and how 3D printing technology affects the rationale of separating production from consumption and locating different manufacturing stages at separate sites? In relation to this geographical configuration of GVCs we specify three determinants: (1) factor cost differentials, (2) scale economies, and (3) factors that are impeding global specialization, including transportation costs, import barriers, technological inseparability.

\section{FACTOR COST DIFFERENTIALS}

Factor-cost differentials, especially labor arbitrage, have driven the offshoring of manufacturing and served as the primary driver of Asia's emergence as a manufacturing hub. In other words, China's huge surplus in exports of manufactured goods to the US is closely related to the wage differential, whichalthough diminishing - is still considerable. However, what if the labor input in additive manufacturing is relatively modest compared to substitutable conventional production? In that case, wage differentials would play a minor role, such that this strong driver of global value chains would lose significance. Therefore, we must establish whether factor inputs, in particular the labor-capital cost ratio, differ significantly between additive manufacturing and conventional production. If so, the next step will be to inquire whether capital-cost differentials on a worldwide basis are comparable or inferior to wage differentials. If interest-rate differentials are similar to the wage differences between countries, then relatively capital-intensive additive manufacturing would locate in destinations other than those used for relatively labor-intensive production, but it would not necessarily move closer to the end-users. In other words, the global specialization of manufacturing would persist, and production would remain geographically separated from end-users. Conversely, if additive manufacturing is more capital intensive than traditional production and the cost of capital differs much less than labor costs across countries, there is less to be gained from global specialization. We will start looking at the labor and capital inputs in additive manufacturing and then proceed to a comparison of labor and capital-cost differentials.

\section{Labor and Capital Inputs of Additive Manufacturing}

Perhaps the most striking feature of 3D printing technology is its potential to reduce the labor input needed for production (of printable products). We can examine this from three different angles depending on which business model prevails. Production may occur (1) in households, (2) in local print shops, or (3) in online print shops - very much as it is today with 2D printing (See Figure 1). 
Preprint: André O. Laplume, Bent Petersen, Joshua M. Pearce, Global value chains from a 3D printing perspective, Journal of International Business Studies 47(5), 595-609 (2016). doi:10.1057/jibs.2015.47

Insert Figure 1 about here

Production in the household is the most extreme case because it eliminates labor costs associated with production (though, not the opportunity costs incurred by the person/people in the household who then have to handle the production). Many 3D printers are designed to be operated by laymen (much like xerography machines and desktop paper printers), removing the need for skill and manual labor associated with component production and assembly processes (Nyman and Sarlin, 2013).

Local print shops are an alternative business model. For example, based on the work of Wittbrodt, et al. (2013), we estimated that an average print on a MOST Prusa RepRap (a common opensource 3D printer) takes about 1.25 hours, yielding about 7 prints per machine per day with a 20 per cent failure rate built in. A singular 3D printer operator could thus generate about 1,820 units a year. However, a single operator can run up to 4 or 5 machines at time, increasing the number of units to 7,280 . Wittbrodt et al. (2013) analyzed a sample of 20 typical household items (retailing for USD 15 on average) printed using a new MOST Prusa RepRap printer (for an average USD 2 cost of materials and electricity per print). Thus, 7,280 units at an average of USD 13 yield USD 109,200 in surplus value. This is a conservative number as more sophisticated printers could enable printing from multiple heads at once greatly expanding this surplus value. Regardless, this number greatly exceeds the yearly value of the labor inherent in traditionally manufactured products. In short the labor costs associated with production using $3 \mathrm{D}$ printers is very small.

Finally, online print shops may be located anywhere with tolerable delivery waits due to distance. For instance, Amazon offers this service today in the U.S. and locates their production within the country (Kentucky). Online print shops tend to utilize high end machines that require a lot of capital. In this case, the capital costs associated with 3D printing are relatively high compared with conventional production. Top end proprietary machines cost hundreds of thousands of dollars, but they can print faster, in more colors, and often with higher quality, further empowering operators to produce a greater quantity and variety of products. These insights lead us to conclude that in general, the labor-/capital-cost ratio in additive manufacturing is low relative to most conventional production.

\section{Capital-Cost Differentials}

Economists have a long tradition of using factor mobility to explain factor-cost differentials. The general contention is that capital is more "footloose" across national borders than labor (Ghemawat, 2011). Therefore, capital costs should diverge less than labor costs. This sounds plausible, but we need to check whether the empirical evidence supports the theory. To do so, we compare the capital-cost differentials 2008-2012 between a group of developed economies (USA, Japan, Germany and the UK) and emerging economies (China, Mexico, Brazil and India) with the labor-cost differentials between the same two groups of countries. As it can be seen from Figure 2 the labor-cost differentials are significantly higher than the capital-cost differentials during the observed time period. ${ }^{7}$

Insert Figure 2 about here

Though the gap between the two groups of countries has been shrinking during the observed 5-year period, in year 2012 - the latest year for which comparable data were available - the labor costs (measured as nominal ${ }^{8}$ hourly pay for workers in the manufacturing sector) in the four developed economies were, on average, still eight times higher than in the four emerging economies. In contrast, and as expected, the 
Preprint: André O. Laplume, Bent Petersen, Joshua M. Pearce, Global value chains from a 3D printing perspective, Journal of International Business Studies 47(5), 595-609 (2016). doi:10.1057/jibs.2015.47

capital-cost differential has been rather modest during the 5-year period. At most, namely in the years 2008 and 2010, the average real interest rate in the emerging economies was double the rate in the developed economies, and in the other three years $(2009,2011,2012)$ the averaged real interest rate was in fact lowest in the emerging economies. Despite the considerable wage inflation in the manufacturing sector of some emerging economies ${ }^{9}$ the labor-cost differential between the developed and emerging economies was disproportionately higher than the capital-cost differential throughout the focal period. To the extent that the cost differentials between the two groups of countries are acceptable proxies for the corresponding gaps between manufacturing in high- and low-cost countries, we can say that the worldwide capital-cost differentials are miniscule compared to differences in labor costs. We therefore conclude that capital-cost differentials across countries are significantly lower than labor-cost differentials.

3D printing is to be considered a highly automated technology with a relatively low labor input. As was accounted for above, capital-costs differentials across countries are much lower than those of labor costs. So, for capital-intensive production, as is 3D printing, factor costs differentials are not really an issue when it comes to localization of production, inasmuch as there is relatively little to gain from locating manufacturing in low cost labor countries like China, Mexico or India. The combination of high capital-intensity and nearby capital cost convergence across countries pulls in the direction of less concentrated (more dispersed) global value chain configuration; in other words, more local production. This alludes to the new opportunities for co-locating production and consumption that the 3D printing technology offers. In those industries and industry segments where 3D printing is both technologically and economically feasible, and the technology diffusion accordingly high, the technology tends to induce small-scale and local production. Hence, there seems to be a need for further research to establish to what extent diffusion of $3 D$ printing technology in an industry associates with more dispersed global value chain configurations?

\section{SCALE ECONOMIES}

In contrast to country-specific factor endowments, scale economies in manufacturing are firm-specific and achievable for all producers that have access to a big enough labor pool and are able to find a sufficiently large market outlet (Weizsäcker, 1993). Since the early days of the industrial revolution, the quest for scale economies has limited possibilities for economical production in close proximity to endusers, often to an extent where a large proportion of firms' customers are located abroad. Moreover, minimum efficient technical scales (METS) vary considerable across manufacturing industries, and some truly innovative "blue ocean" producers may be relaxed about the need for efficient scales and other cost issues (Kim and Mauborgne, 2005). Still, traditional manufacturing and price competition require large production series for manufactured goods, such as white goods, domestic appliances, sport shoes, and laptops, which are typically produced in global value chains (Hobday, 1995; Piore \& Duràn, 1998). However, what if METSs are significantly lower for additive manufacturing than for traditional production? In that case, scale economies, which are on par with factor-cost differentials as an important antecedent of global value chains, would no longer constitute a pivotal cost advantage in manufacturing. Therefore, in order to make inferences regarding how additive manufacturing may affect global value chains, we must first establish whether additive manufacturing is less sensitive to scale economies than traditional production.

\section{Scale economies in additive manufacturing}

In general, manufacturers employ two strategies to facilitate product customization. The first involves the creation of modular product architectures. The second involves the use of generalist machines that can produce high variety (e.g., CNC cutting machines) (Baldwin \& Clark, 2000; Mikkola, 2003; Volberda, 1998). 3D printers, which fall into the second category, are highly generalized machines. They can fabricate products with complex geometries that would normally require highly specialized production 
Preprint: André O. Laplume, Bent Petersen, Joshua M. Pearce, Global value chains from a 3D printing perspective, Journal of International Business Studies 47(5), 595-609 (2016). doi:10.1057/jibs.2015.47

technologies or that might be impossible to manufacture using conventional techniques. This makes 3D printers especially well suited to the task of customization, as they can produce a wide range of products without retooling or reconfiguration. Unlike traditional manufacturing techniques in which many different molds are needed to produce variety, 3D printers can produce extremely high variety without additional manufacturing costs (Nyman and Sarlin, 2013).

The customizability of open-source 3D printers makes the creation of very small batches possible, opening up the possibility of business models catering to customers who desire highly distinct prints (i.e., personalized applications). For example, Pearce (2014) and Baden et al. (2015) highlight how scientists may exploit the technology to print their own scientific equipment at significantly reduced cost. For example, a USD 15,000 optics lab may be reduced to a USD 500 print job on a RepRap that itself costs less than USD 1,000 (Zhang, Anzalone, Faria, \& Pearce, 2013) or similarly replacing a USD 2,000 handheld water quality tester for under USD 100 (Wijnen, Anzalone \& Pearce, 2014). Thus, the cost of the 3D printer is low enough to justify buying one to print a single high-value item , creating substantial investment returns for scientists (Pearce, 2015). In contrast, most specialized manufacturing technologies require the production of many units to justify their costs. Therefore, we conclude that, in general, minimum efficient technical scale in additive manufacturing is low relative to conventional production. Thus, future research might seek to answer the question: as 3D printing diffuses in an industry, to what extent will scale economies be eroded by the technology and how will this erosion change MNEs' role in coordinating GVC? There is an equally pressing need for studying regional effects: Do production clusters based on scale economies and cheap, abundant labor lose out as a consequence of the new technology? Does this suggest denser networks of increasingly localized producers (e.g., households and local print shops)?

\section{FACTORS IMPEDING GLOBAL SPECIALIZATION}

Factors impeding global specialization of production include technological inseparability, transportation costs and import barriers. In the following we account for each of these factors.

\section{Technological Inseparability}

Intermediate goods make up a large share of international trade between divisions of MNEs, and between MNEs and their partners (Kumar, 1994). Trade in intermediate goods is associated with firms' vertical disintegration strategies (Kleinert, 2003). One of the key advantages of 3D printing is that it offers the ability to print a "whole" product, thereby not only eliminating the need for assembly but also reducing the need for intermediate goods. Examples include: toys, game pieces, sporting equipment, shoes and fashion items, home accessories, scientific equipment components, art and collectables. 3D printing often allows raw materials to be converted directly into finished goods. Value chains are affected by how many intermediate goods must be included. For instance, there are often three tiers of suppliers to automobile assemblers. Tier 1 might supply a whole car interior, Tier 2, a Seat, and Tier 3, some leather. The value chain in this case consists of three technologically separable processes that might be located in different sites. In the case of 3D printing, the interior and exterior of the car would be printed all in one shot (e.g., Local Motors), and there is only need for plug-and-play add-ons. Hence, 3D printing implies technological inseparability.

We, therefore, conclude that relative to existing production, additive manufacturing of finished goods implies existing value chains become more compressed, reducing alternatives in terms of allocating tasks across a set of independent producers. 3D printing technology creates 'whole' products with few intermediate goods - implying a leapfrogging of the production of intermediate products. The bottom line is shorter global value chains including manufacturing (3D printing) of finished goods preceded by raw material extraction, processing and distribution. Nonetheless, future research is needed to confirm whether or not diffusion of $3 D$ printing technology in an industry associates with shorter global value 
Preprint: André O. Laplume, Bent Petersen, Joshua M. Pearce, Global value chains from a 3D printing perspective, Journal of International Business Studies 47(5), 595-609 (2016). doi:10.1057/jibs.2015.47

chains because production of intermediate goods is leapfrogged. Will there be a reduction in the density of value chains, and a reduction of their span (i.e., closer to the customer)?

Furthermore, the emergence of more (local) production sites as a result of adoption of 3D printing technology generates a need for a more dense and widespread raw material supply system-i.e., shipping many small lots to more locations rather than large lots to fewer locations. Thus, future research might examine: To what extent diffusion of $3 D$ printing in an industry associates with more dispersed value chains in terms of raw material supplies? ${ }^{10}$

3D printing technology tends to demotivate MNE coordination of the upstream (i.e. manufacturing) parts of global value chains-not so much the downstream parts (i.e. marketing and sales) and certainly not the very upstream parts: namely the extraction, processing, and distribution of raw materials. Thus, control of raw material supplies will become more critical in global production networks adopting additive manufacturing technology. Hence we put forth a related question: To what extent does adoption of 3D printing technology in global value chains accentuate the coordinating role of MNEs in control of raw material supplies?

\section{Transportation Costs and Import Barriers}

Needless to say, transportation costs and import barriers induce local manufacturing at the expense of imports from global production hubs. In most countries, tariff barriers for manufactures are increasing with value and/or processing degree. Hence, imports of finish goods are imposed higher tariffs than imported intermediate goods, which in turn are imposed higher tariffs than imports of industrial raw materials. Such a tariff escalation system (WTO, 2015), devised to support an import substitution policy by protecting domestic production, is favorable to 3D printing because the inputs are low-tariffed raw materials rather than higher-tariffed intermediate goods. In other words, the 3D printing features of bypassing intermediates are in general rewarded by the tariff systems and gives, ceteris paribus, additive manufacturing an economic advantage over other manufacturing technologies. In contrast, it is less clear how transportation costs affect the diffusion of 3D printing technology vis-à-vis other manufacturing technologies, but to the extent that METS of 3D printing is low relative to conventional manufacturing high transportation costs will, all else being equal, favor 3D printing. Thus, an interesting research question might be: To what extent does 3D printing reduce the burdens of trade tariffs and transportation costs? Also, studies of 3D technology's effects on the transport sector, in particular international shipping, are indeed warranted. It follows from our reasoning that we can expect a surge in transportation of raw materials at the expense of carriage of intermediate goods.

\section{CONCLUSION}

As was pointed out in our account of the technological scope of additive manufacturing the applicability of 3D printing technology varies considerably across the different industries in the manufacturing sector. 3D printing is highly applicable in certain industries, such as manufacturing of machinery and equipment, whereas other industries, including the manufacture of basic metals, chemicals, paper products and textiles are unlikely to be affected in any foreseeable future. It is also clear that technological feasibility is a necessary, but not sufficient condition for diffusion; in some industries or industry segments 3D printing is technologically, but not economically feasible. This goes for industries or industry segments characterized by high METS and long production series and/or industry segments where manufacturing is already highly automated. Conversely, in industry segments with low METS, short production runs and low degree of automation, adoption of 3D printing technology may be pervasive. We mentioned the manufacturing of wearing apparel as one example of an industry that comprises industry segments of both types. It is also important to keep in mind that the 3D printing technology itself may define new production paradigms inasmuch as this technology in some industries sets new and lower METS standards. 
Preprint: André O. Laplume, Bent Petersen, Joshua M. Pearce, Global value chains from a 3D printing perspective, Journal of International Business Studies 47(5), 595-609 (2016). doi:10.1057/jibs.2015.47

We have raised questions about the future implications of open-source additive manufacturing technology for the configuration of global value chains. Given the explorative nature of our study we could not get near a definite answer to this question, but only provide some indicative suggestions. This said, our study suggests that diffusion of 3D printing technology in an industry is associated with a development towards shorter and more dispersed global value chains. Hence, in some industries the new manufacturing technology is likely to pull manufacturing value chains in the direction of becoming more local, and closer to the end-users. Furthermore, the technology induces the engagement of a wider variety of firms (local and online print shops), as well as households, in manufacturing. Also, MNEs feeding global value chains with raw materials are assigned a more potent role as additive manufacturing technology diffuses because of the need to delivery small batches to more players.

Although additive manufacturing already has gone through an amazing development the technology is still in its infancy. It is, therefore, difficult to make accurate predictions about how disruptive the new technology will actually be. As such, our study is truly explorative and presumably raises more questions than answers. Thus, our premises about the 3D printing technology are far from being 'stylized fact', but should rather be seen as attempts to lay a structure for analyzing the implications to international business of this emergent manufacturing technology. Surely, there are opportunities for, and limits to, this technology which may not have come out clearly in our paper. Our general-level analyses call for appending product- and industry-specific research on how global value chains are affected by the new technology.

As a last, important, limitation of the study we should mention that we have only touched on the issue of sustainability of the technology, but there seems to be an obvious need for recycling technologies to keep pace with the diffusion of 3D printers, or the technology may serve to increase the proliferation of waste. If recycling technologies do not keep up, then low cost 3D printing might be creating an evergrowing pile of trash. This problem already exists with traditional manufacturing, and may be aggravated.

\section{REFERENCES}

Anzalone, G.C., Wijnen, B., \& Pearce, J.M. 2015. Multi-material additive and subtractive prosumer digital fabrication with a free and open-source convertible delta RepRap 3-D printer, Rapid Prototyping Journal, 21(5). http://www.emeraldinsight.com/doi/abs/10.1108/RPJ-09-2014-0113

Anzalone, G.C., Zhang, C., Wijnen, B., Sanders, P.G., \& Pearce, J.M. 2013. A low-cost open-source metal 3D Printer. IEEE Access, 1, 803-810.

Baden, T., Chagas, A. M., Gage, G., Marzullo, T., Prieto-Godino, L. L., \& Euler, T. 2015. Open labware: 3-D printing your own lab Equipment. PLOS Biology, 13(3). DOI: 10.1371/journal.pbio.1002086

Baechler, C., DeVuono, M., \& Pearce, J. M. 2012. Distributed recycling of waste polymer into reprap feedstock. Rapid Prototyping Journal. 19(2): 7-7.

Baldwin, C., \& Clark, K. B. 2000. Design Rules: Volume I, The Power of Modularity. Cambridge: MIT Press.

Berman, B. 2012. 3D printing: The new industrial revolution. Business Horizons. 55(2): 155-162.

Bowyer, A. 2014. 3D Printing and humanity's first imperfect replicator. 3D Printing and Additive Manufacturing, 1(1): 4-5. 
Preprint: André O. Laplume, Bent Petersen, Joshua M. Pearce, Global value chains from a 3D printing perspective, Journal of International Business Studies 47(5), 595-609 (2016). doi:10.1057/jibs.2015.47

Bradshaw, S., Bowyer, A., \& Haufe, P. 2010. The intellectual property implications of low-cost 3D printing. ScriptEd. 7(1): 5-31.

Buckley, P. J., \& Ghauri, P. N. 2004. Globalisation, economic geography and the strategy of multinational enterprises. Journal of International Business Studies, 35(2): 81-98.

Chesbrough, H., 2003. Open Innovation: The new imperative for creating and profiting from technology. Harvard Business School Press, Boston.

CNBC. 2013. The 'gold rush' for 3D printing patents. http://www.cnbc.com/id/100942655, accessed December 2013.

Danneels, E. 2004. Disruptive Technology Reconsidered: A Critique and Research Agenda. Journal of Product Innovation Management, 21(4): 246-258.

Dedrick, J., Kraemer, K. L., \& Linden, G. 2010. Who profits from innovation in global value chains?: A study of the iPod and notebook PCs. Industrial and Corporate Change. 19(1): 81-116.

Dicken, P. 2014. Global Shift: Mapping the Changing Contours of the World Economy. Sage Publications.

Driscoll, C., \& Starik, M. 2004. The primordial stakeholder: Advancing the conceptual consideration of stakeholder status for the natural environment. Journal of Business Ethics. 49(1): 55-73.

Dunning, J. H. 2001. The eclectic (OLI) paradigm of international production: past, present and future. International journal of the economics of business. 8(2): 173-190.

Dunning, J.H. 1993. Multinational Enetrprises and the Global Economy. Addison-Wesley.

The Economist. 2012. A third industrial revolution: Special Report: Manufacturing and innovation, The Economist.

Ethical Filament Foundation. 2013. http://www.ethicalfilament.org/, accessed Dec. 2013.

Flaterty, J. 2014. This dress is made from 3D printed plastic, but flows like fabric. Wired Magazine, http://www.wired.com/2014/12/dress-made-3D-printed-plastic-flows-like-fabric/ (accessed February 2015).

Foss, N. J., \& Pedersen, T. 2004. Organizing knowledge processes in the multinational corporation: an introduction. Journal of International Business Studies. 35: 340-349.

Ghemawat, P. 2011. World 3.0 - Global Prosperity and How to Achieve It. Boston, Massachusetts: Harvard Business Review Press.

Gereffi, G., Humphrey, J., \& Sturgeon, T. 2005. The governance of global value chains. Review of international political economy, 12(1): 78-104

Gershenfeld, N. 2008. Fab: the coming revolution on your desktop--from personal computers to personal fabrication. Basic Books. 
Preprint: André O. Laplume, Bent Petersen, Joshua M. Pearce, Global value chains from a 3D printing perspective, Journal of International Business Studies 47(5), 595-609 (2016). doi:10.1057/jibs.2015.47

Globerman, S., Roehl, T. W., \& Standifird, S. 2001. Globalization and electronic commerce: inferences from retail brokering. Journal of International Business Studies. 32(4): 749-768.

Ghoshal, S., \& Bartlett, C. 1998. The Individualized Corporations. London: Heinemann.

Hobday, M. 1995. East Asian Latecomer Firms: Learning the Technology of Electronics. World Development 23(7): 1171-1193.

Hopkinson, N., Hague, R., \& Dickens, P. (Eds.). 2006. Rapid manufacturing: an industrial revolution for the digital age. John Wiley \& Sons.

Huizingh, E. K. 2011. Open innovation: State of the art and future perspectives. Technovation. 31(1): 2-9.

Hull, C. 1986. Apparatus for production of three-dimensional objects by stereolithography, U.S. Patent 4,575,330.

Hunt, E. J., Zhang, C., Anzalone, N., \& Pearce, J. M. 2015. Polymer recycling codes for distributed manufacturing with 3-D printers. Resources, Conservation and Recycling, 97: 24-30.

Jones, R., Haufe, P., Sells, E., Iravani, P., Olliver, V., Palmer, C., \& Bowyer, A. 2011. Reprap - the replicating rapid prototyper. Robotica, 29(1), 177-191.

Jovanovic, B., \& Rousseau, P. L. 2005. General purpose technologies. Handbook of Economic Growth, 1, 1181-1224.

Kim, W.C., \& Mauborgne, R. 2005. Blue Ocean Strategy: How to Create Uncontested Market Space and Make the Competition Irrelevant. Boston: Harvard Business School Press.

Kitson, P. J., Rosnes, M. H., Sans, V., Dragone, V., \& Cronin, L. 2012. Configurable 3D-Printed millifluidic and microfluidic 'lab on a chip'reactionware devices. Lab on a chip, 12(18): 3267-3271.

Kitson, P. J., Symes, M. D., Dragone, V., \& Cronin, L. 2013. Combining 3D printing and liquid handling to produce user-friendly reactionware for chemical synthesis and purification. Chemical Science, 4(8): 3099-3103.

Kleinert, J. 2003. Growing trade in intermediate goods: outsourcing, global sourcing, or increasing importance of MNE networks? Review of International Economics, 11(3): 464-482.

Kreiger, M. Anzalone, G. C., Mulder, M. L., Glover, A. \& Pearce, J.M. 2013. distributed recycling of post-consumer plastic waste in rural areas. MRS Online Proceedings Library, 1492, mrsf12-1492-g04-06.

Kreiger, M.A., Mulder, M.L., Glover, A.G., \& Pearce J. M., 2014. Life Cycle Analysis of Distributed Recycling of Post-consumer High Density Polyethylene for 3D Printing Filament, Journal of Cleaner Production, 70(1): 90-96.

Kumar, N. 1994. Determinants of export orientation of foreign production by US multinationals: An intercountry analysis. Journal of International Business Studies, 25(1): 141-156. 
Preprint: André O. Laplume, Bent Petersen, Joshua M. Pearce, Global value chains from a 3D printing perspective, Journal of International Business Studies 47(5), 595-609 (2016). doi:10.1057/jibs.2015.47

Lee, H. and Tang, C. 1997. Modelling the Costs and Benefits of Delayed Product Differentiation. Management Science, 43(1): 40-53.

Lipson, H., \& Kurman, M. 2013. Fabricated: the new world of 3D printing. John Wiley \& Sons.

Lussenburg, K., Van der Velden, N. M., Doubrovski, E. L., Geraedts, J. M. P., \& Karana, E. (2014, October). Designing with 3D Printed Textiles: A case study of Material Driven Design. In iCAT 2014: Proceedings of the 5th International Conference on Additive Technologies, Vienna, Austria, 16-17 October 2014. Interesansa-zavod.

Maskell, P., Pedersen, T., Petersen, B., \& Dick-Nielsen, J. 2007. Learning Paths to Offshore Outsourcing - From Cost Reduction to Knowledge Seeking, Industry and Innovation, 14(3): 239-257.

Mehrabi, M.G., Ulsoy, A.G. and Koren, Y. 2000. Reconfigurable manufacturing systems: Key to future manufacturing. Journal of Intelligent Manufacturing, 11: 403-419.

METI, (2002). METI White Paper Year 2001. http://www.meti.go.jp/english/report/index.html. Database of the METI website accessed August 2014.

Mikkola, J.H. 2003. Modularity, component outsourcing, and inter-firm learning. R\&D Management, 33(4): 439-454.

Moilanen, J., \& Vadén, T. 2013. 3D printing community and emerging practices of peer production. First Monday, 18(8).

Mudambi, R. 2008. Location, Control and Innovation in Knowledge-Intensive Industries. Journal of Economic Geography, 8(5): 699-725.

New York Times Magazine, 11.11.2012 http://www.nytimes.com/2012/11/11/magazine/how-zara-grewinto-the-worlds-largest-fashion-retailer.html?pagewanted=all\& r=1\&pagewanted=print

Nyman, H. J., \& Sarlin, P. 2013. From bits to atoms: 3D printing in the context of supply chain strategies. Working Paper.

Opam, K. 2014. Watch this 3D printer make pizza fit for astronauts. The Verge, http://www.theverge.com/2014/1/24/5342180/watch-this-3d-printer-make-pizza-fit-for-astronauts (accessed February, 2015).

Oviatt, B. M., \& McDougall, P. P. (1994). Toward a theory of international new ventures. Journal of International Business Studies. 25(1): 45-64.

Pearce, J. M. 2014. Open-source lab: How to build your own hardware and reduce research costs. Elsevier.

Pearce, J. M. 2015. Return on investment for open source hardware development. Science and public policy. DOI :10.1093/scipol/scv034

Pine, B.J. 1995. Mass Customization - The New Frontier in Business Competition. Harvard Business School Press, Boston, MA. 
Preprint: André O. Laplume, Bent Petersen, Joshua M. Pearce, Global value chains from a 3D printing perspective, Journal of International Business Studies 47(5), 595-609 (2016). doi:10.1057/jibs.2015.47

Piore, M., \& Ruiz Duràn, C. 1998. Industrial Development as a Learning Process: Mexican Manufacturing and the Opening to Trade. In M. Kagami, J. Humphrey, \& M. Piore (eds.) Learning, Liberalisation and Economic Adjustment, Tokyo: Institute of Developing Economies: 191-241

Porter, M.E. 1985. Competitive Advantage - Creating and Sustaining Superior Performance. The Free Press, New York.

Porter, M.E. 1986. Competition in global industries: A conceptual framework. In M. E. Porter (Ed.), Competition in Global Industries, pp. 15-60. Cambridge, MA, USA: Harvard Business School Press.

RepRap.org, 2012. RepRap Family. http://reprap.org/wiki/RepRap Family Tree, accessed December, 2013.

Ricardo, D. 1817. On the Principles of Political Economy and Taxation. London: John Murray, retrieved July 2014 via Google Books.

Scheithauer, U., Schwarzer, E., Richter, H. J., \& Moritz, T. 2015. Thermoplastic 3D Printing-An Additive Manufacturing Method for Producing Dense Ceramics. International Journal of Applied Ceramic Technology, 12(1): 26-31.

Sells, E., Bailard, S., Smith, Z., Bowyer, A. 2010. Reprap: the replicating rapid prototype: maximizing curstomizability by breeding the means of production. In: Piller, F.T., Tseng, M.M., editors.

Handbook of research in mass customization and personalization: strategies and concepts, Vol. 1. World Scientific; 2010. pp.568-80.

Smith, A. 1776. An inquiry into the nature and causes of the wealth of nations. London: George Routledge and Sons.

Symes, Mark D., Philip J. Kitson, Jun Yan, Craig J. Richmond, Geoffrey JT Cooper, Richard W. Bowman, Turlif Vilbrandt, \& Leroy Cronin. 2012. Integrated 3D-printed reactionware for chemical synthesis and analysis. Nature Chemistry. 4(5): 349-354.

Tushman, M.L \& Anderson, P. 1986. Technological Discontinuities and Organizational Environments. Administrative Science Quarterly, 31(3): 439-465.

UNCTAD. 2013. World Investment Report 2013. Global Value Chains: Investment and Trade for Development. United Nations, New York and Geneva.

Volberda, H.W. 1998. Building the flexible firm. Oxford: Oxford University Press.

von Weizsäcker, C. 1993. The Division of Labour and Market Structure. Empirica, 20(3): 241-244.

Wijnen, B., Anzalone, G. C., \& Pearce, J. M. 2014. Open-source mobile water quality testing platform. Journal of Water, Sanitation and Hygiene for Development, 4(3): 532-537. 
Preprint: André O. Laplume, Bent Petersen, Joshua M. Pearce, Global value chains from a 3D printing perspective, Journal of International Business Studies 47(5), 595-609 (2016). doi:10.1057/jibs.2015.47

Wittbrodt, B. T., Glover, A. G., Laureto, J., Anzalone, G. C., Oppliger, D., Irwin, J. L., \& Pearce, J. M. 2013. Life-cycle economic analysis of distributed manufacturing with open-source 3D printers. Mechatronics. 23(6): 713-726.

WTO World Trade Organization. International Trade Statistics 2013, http://www.wto.org/statistics

WTO, World Trade Organization 2015. Understanding The WTO: Developing Countries, https://www.wto.org/English/thewto e/whatis e/tif e/dev4 e.htm

Yu, D., \& Hang, C.C. 2011. Creating technology candidates for disruptive innovation: Generally applicable R\&D strategies. Technovation. 31(8): 401-410.

Zhang, C., Anzalone, N.C., Faria, R.P., \& Pearce, J.M. 2013. Open-Source 3D-Printable Optics Equipment. PLoS ONE 8(3): e59840. 
Preprint: André O. Laplume, Bent Petersen, Joshua M. Pearce, Global value chains from a 3D printing perspective, Journal of International Business Studies 47(5), 595-609 (2016). doi:10.1057/jibs.2015.47

Table 1: 3D printing as patented versus open-source technology

\begin{tabular}{|c|c|}
\hline Patented 3D tedmology & Opensource 3. Dtechnology \\
\hline Fused Deposition Modeling $^{T M}$ (FDM) & Fused Filament Fabrication (FFF) \\
\hline Slow technical evolution & Weekly improvements \\
\hline Plastic 3-D printers > USD 20k+ & RepRaps < USD 1k \\
\hline Very limited competition & Dozens of companies USD 400-3k \\
\hline $\begin{array}{l}\text { Proprietary feedstock } \\
\text { (even when it is common plastic) }\end{array}$ & $\begin{array}{l}\text { Wide variety of feedstock } \\
\text { (even waste plastic) }\end{array}$ \\
\hline Solar test case: USD 65 & Solar test case < USD 5 \\
\hline
\end{tabular}


Preprint: André O. Laplume, Bent Petersen, Joshua M. Pearce, Global value chains from a 3D printing perspective, Journal of International Business Studies 47(5), 595-609 (2016). doi:10.1057/jibs.2015.47

Table 2: Diffusion of 3D printing technology in different manufacturing industries (ISIC)

\begin{tabular}{|c|c|c|}
\hline & Today & In the Future \\
\hline $\begin{array}{l}\text { No, or low, } \\
\text { industry } \\
\text { diffusion }\end{array}$ & $\begin{array}{l}10 \text { - Mfg. of food products } \\
14 \text { - Mfg. of wearing apparel } \\
18 \text { - Printing and reproduction of recorded media } \\
25 \text { - Mfg. of fabricated metal products, except } \\
\text { machinery and equipment } \\
26 \text { - Mfg. of computer, electronic and optical products } \\
27 \text { - Mfg. of electrical equipment } \\
29 \text { - Mfg. of motor vehicles, trailers and semi-trailers } \\
30 \text { - Mfg. of other transport equipment } \\
31 \text { - Mfg. of furniture }\end{array}$ & $\begin{array}{l}11 \text { - Mfg. of beverages } \\
12 \text { - Mfg. of tobacco products } \\
13 \text { - Mfg. of textiles } \\
15 \text { - Mfg. of leather and related products } \\
16 \text { - Mfg. of wood and of products of wood and cork, } \\
17 \text { - Mfg. of paper and paper products } \\
19 \text { - Mfg. of coke and refined petroleum products } \\
20 \text { - Mfg. of chemicals and chemical products } \\
24 \text { - Mfg. of basic metals }\end{array}$ \\
\hline $\begin{array}{l}\text { High } \\
\text { industry } \\
\text { diffusion }\end{array}$ & $\begin{array}{l}23 \text { - Mfg. of other non-metallic mineral products } \\
22 \text { - Mfg. of rubber and plastics products } \\
28 \text { - Mfg. of machinery and equipment n.e.c. } \\
32 \text { - Other Mfg. } \\
33 \text { - Repair and installation of machinery and } \\
\text { equipment }\end{array}$ & $\begin{array}{l}10 \text { - Mfg. of food products } \\
14 \text { - Mfg. of wearing apparel } \\
18 \text { - Printing and reproduction of recorded media } \\
21 \text { - Mfg. of pharmaceuticals, medicinal chemical } \\
23 \text { - Mfg. of other non-metallic mineral products } \\
25 \text { - Mfg. of fabricated metal products, except } \\
\text { machinery and equipment } \\
26 \text { - Mfg. of computer, electronic and optical } \\
\text { products and botanical products } \\
27 \text { - Mfg. of electrical equipment } \\
29 \text { - Mfg. of motor vehicles, trailers and semi-trailers } \\
30 \text { - Mfg. of other transport equipment } \\
31 \text { - Mfg. of furniture }\end{array}$ \\
\hline
\end{tabular}


Preprint: André O. Laplume, Bent Petersen, Joshua M. Pearce, Global value chains from a 3D printing perspective, Journal of International Business Studies 47(5), 595-609 (2016). doi:10.1057/jibs.2015.47

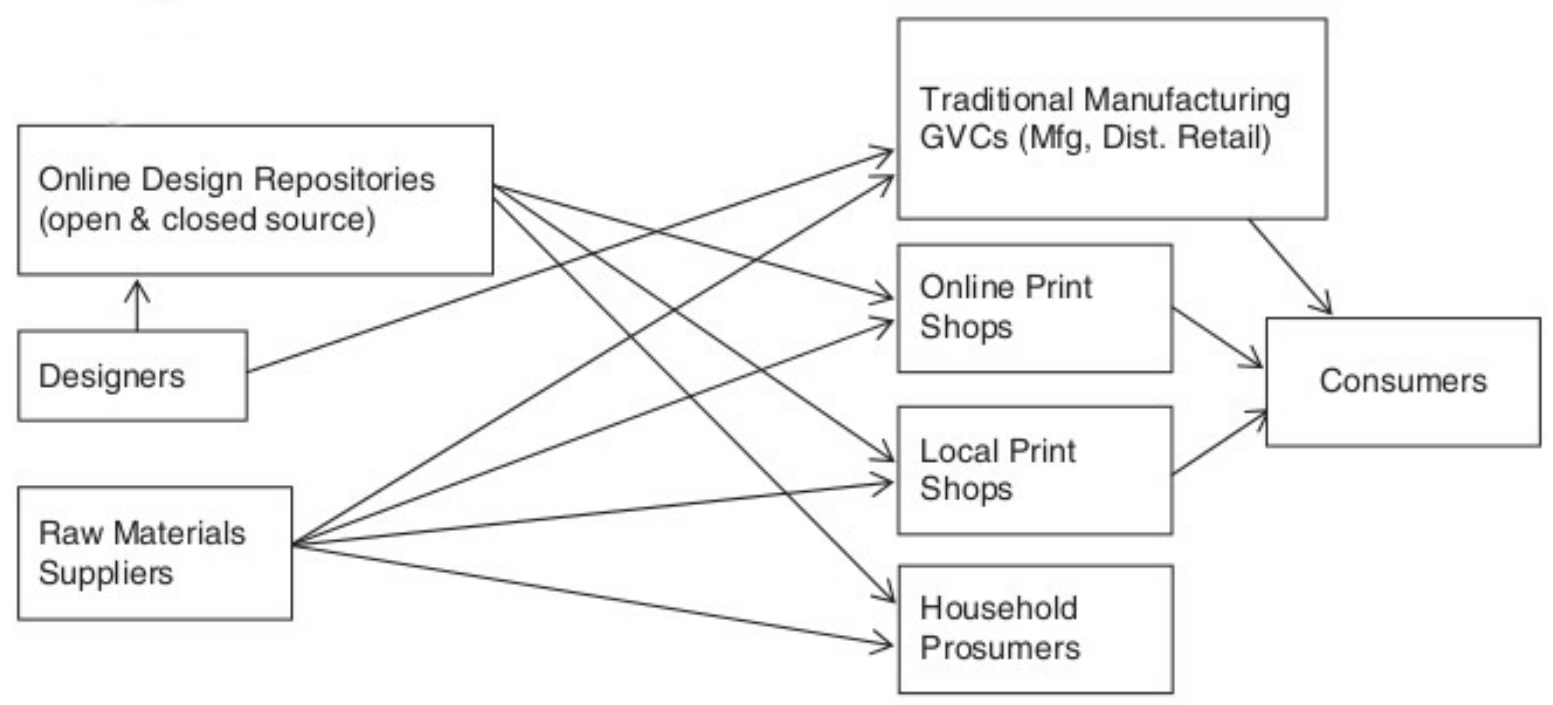

Figure 1: The 3D Printing Value Chain. 
Preprint: André O. Laplume, Bent Petersen, Joshua M. Pearce, Global value chains from a 3D printing perspective, Journal of International Business Studies 47(5), 595-609 (2016). doi:10.1057/jibs.2015.47

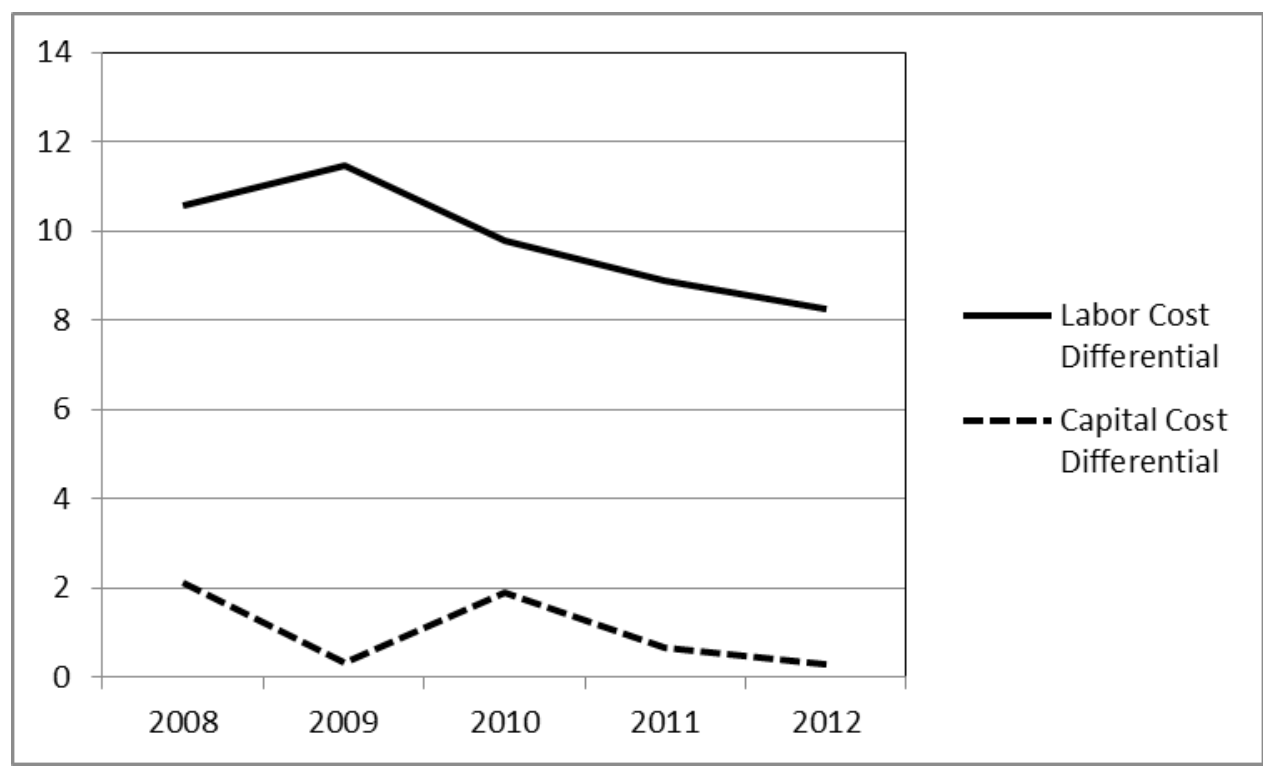

Figure 2: Labor and capital cost differentials 2008-2012 between developed market countries and emerging market countries

(Data sources: Labor cost statistics: https://www.conference-board.org/ilcprogram/index.cfm?id=28277\#Table1 Japanese import statistics: https://www.jetro.go.jp/en/reports/statistics/; German and UK import statistics: http://madb.europa.eu/madb/statistical form.htm; US import statistics: http://tse.export.gov/tse/MapDisplay.aspx; Real interest statistics for Brazil, China, India, Mexico, UK, US and Japan: http://www.indexmundi.com/facts/indicators/FR.INR.RINR/compare\#country=br:cn:in:mx; Real interest for Germany: https://www.euro-area-statistics.org/bank-interest-rates-loans?cr=eur\&cr1=eur\&lg=en\&page=2 https://www.euro-area-statistics.org/inflation-rates?cr=eur\&lg=en. The data and resulting figures are available on request).

\section{Endnotes}


The high price tags on these machines may have primarily resulted from intellectual property-protection regimes, rather than technical costs. For example, one of the simplest 3D printing techniques uses a filament of plastic, which is melted and used to trace out successive 2D layers—very much like a robot-controlled hot glue gun. This process, which is patented and trademarked by Stratasys, is called fused-deposition modeling (FDM).

2 http://www.theatlantic.com/technology/archive/2013/11/almost-no-one-buys-3d-printers/281297/. 5,925 (Makerbots sold in six weeks of 2013) x 8 (six-week periods) x 400\% (Makerbot market share estimated at 25\%). It should be noted Makerbot is now a proprietary product. http://reprage.com/post/35354576225/how-many-consumer-3d-printers-havebeen-sold/. 70,000 3D printers sold prior to 2013.

${ }^{3}$ For a more complete list of design-file sources, see http://reprap.org/wiki/Printable part sources.

4 According to CNBC (2013:1), "Since 2007, about 680 patents a year have been filed—39.6 percent more than 2002, when 487 patents were filed. Since 2003, the [U.S. patent] office has granted 3,500 patents related to 3-D printing.”

${ }^{5}$ See http://3dprint.com/2554/uss-essex-3d-printer-navy/

${ }^{6}$ Considering the cost and vulnerabilities of its logistics and supply chains, one of the biggest shipping companies, Maersk, has purchased uPrint SE 3D printers from Stratasys. The uPrint SE 3D printers use Fused Deposition Modeling (FDM) Technology to build 3D parts in ABS thermoplastic and can be used to produce durable spare parts right from desktop. In the future, 3D printers could be used to print out spare or repair parts for the company's large, ocean-going oil tankers, and the digital blueprint could be downloaded from anywhere in the world (http://www.3ders.org/articles/20140713-3dprinting-could-revolutionize-supply-chains-at-maersk.html)

7 The labor- and capital-cost differentials are based on weighted figures for four large developed market countries (USA, Japan, Germany and the UK) and four large emerging market countries (China, Mexico, Brazil and India) for the five years 2008-2012. For each of the five years a composite figure for labor and capital costs was calculated as a weighted average of the four developed market countries, respectively the four emerging market countries. The differential appears by dividing the weighted average for developed market countries by the weighted average for the emerging market countries. The weight used for each of the four developed market countries was its share of the four countries' total import 
of merchandises from the four emerging market countries. Correspondingly, the weight used for each of the four emerging market countries was its share of the four countries' total export of merchandises to the four developed market countries.

The figure for the Indian labor costs in year 2012 was created by an extrapolation of the figures for the four preceding years.

8 Ideally, labor costs should not be measured in nominal terms but as real wages, taking the average productivity of workers into account. The conventional measure of labor productivity, which is calculated as GDP divided by the number of employed people, largely ignores the possibility that low wages can be explained by factors other than low productivity, such as a country’s high purchasing power parity; no or low minimum wages; excess labor supply; weak or non-existent trade unions; fierce cost competition among employers; or unfavorable terms of trade, which imply high producer and consumer surpluses accruing to foreign buyers. One might recognize several of these institutional and macro-economic factors as characterizing emerging economies. However, there are many technical problems associated with developing a labor productivity measure that takes all of these factors into account. As an example, the US Bureau of Labor Statistics has abstained from preparing level comparisons of manufacturing productivity for these reasons, see http://www.bls.gov/ilc/\#productivity.

9 As an example, the hourly pay of workers in the Chinese manufacturing sector almost doubled from 2008 to 2012 (from USD 1.59 to 3.07), see https://www.conference-board.org/ilcprogram/index.cfm?id=28277\#Table1). Hence, Chinese manufacturers are impelled to migrate to other Asian countries, such as Vietnam, the Philippines and Indonesia, where the opportunities for labor arbitrage are sufficient to maintain their position in global value chains (Dicken, 2014).

${ }^{10}$ 3D material recycling technology may affect this reasoning. Open-source "RecycleBots", or waste plastic extruders capable of making 3D printer feedstock have already been developed and preliminary studies have shown both economic and environmental benefits (Baechler, DeVuono, \& Pearce, 2012; Kreiger, Anzalone, Mulder, Glover \& Pearce, 2013). Recycling devices (e.g., Filastruder, Filabot, and Filafab), have had successful kick-starter campaigns, but are not very widely commercialized and are much less developed than 3D printers. Thus, in the short term, small 3D printers, widely diffused by inexperienced operators invite the potential for both failed prints and overproduction resulting in clutter and increased waste. Recycling lowers embodied energy per kg of material, and increases material availability, suggesting that it can lead to more sustainable relations between industries and the natural environment (Driscoll \& Starik, 2004; Kreiger et al., 2013; Kreiger, Mulder, Glover, \& Pearce, 2014). It also has implication for global value chains, especially location advantages current being enjoyed by raw material providers. Local recycling emphasizes locally available inputs reducing the need for movement of materials and provides the potential for new forms of sustainable development by increasing wages of waste pickers, see recent work by the Ethical Filament Foundation, 2013 and the Plastic Bank http://plasticbank.org/ 